\title{
Drogas en la contemporaneidad: 100 miligramos de reflexiones ${ }^{1}$
}

Jaime Alonso Caravaca Morera ${ }^{2}$

Institución: Universidad Federal de Santa Catarina

\section{ENSAYO}

\section{COMO CITAR}

Caravaca, J.A. (2016). Drogas en la contemporaneidad: 100 miligramos de reflexiones. Rev. Enfermería Actual en Costa Rica, 31 , 1-15. DOI: http://dx.doi.org/10.15517/revenf.v0i31.22826

\section{RESUMEN}

Introducción: El siguiente estudio delimitó como objetivo reflexionar sobre el fenómeno del consumo de drogas, tomando como eslabón vinculante el caso del crack en la actualidad.

Desarrollo: El escándalo vinculado al fenómeno del consumo de drogas no reside en la ilegalidad de la acción, ni en los riesgos de daños a la salud o en la cooperación financiera con las transiciones criminosas; por esta razón, para su análisis deben ser estudiadas otras variables contextuales relacionadas a la contemporaneidad del acto en sus diferentes dimensiones económicas, sociales, políticas, semánticas y representacionales.

Conclusiones: Las drogas vistas como productos mercantiles, deben ser tratadas como tales, no solo porque se encuentran inmersas en un proceso de acumulación en una sociedad que presenta características estrictamente post-coloniales y capitalistas; sino que su comportamiento de intercambio, consumo, oferta y demanda, las hace responder a esa realidad intrínseca propia de las mercadurías En este sentido, el análisis del fenómeno de las drogas debe ser realizado a partir de su particularidad histórica y contextualizada a las diversas implicaciones de las cuales proceden.

Palabras clave: crack, drogas, drogas-ilícitas, drogas-lícitas

\footnotetext{
${ }^{1}$ Fecha de recepción: 14 de enero del 2016

Fecha de aceptación: 25 de mayo del 2016

${ }^{2}$ Enfermero. Doctorando en Enfermería en el Programa de Post-Grado en Enfermería de la Universidad Federal de Santa Catarina,
Brasil (PEN/UFSC). Correo electrónico: jaimealonso.caravaca@ucr.ac.cr
} 


\section{Drug contemporaneity: 100 milligrams of reflections ${ }^{1}$}

Jaime Alonso Caravaca Morera ${ }^{2}$

Institution: Federal the Santa Catarina University

\section{ESSAY}

\section{CITED}

Caravaca, J.A. (2016). Drug contemporaneity: 100 milligrams of reflections. Rev. Enfermería Actual en Costa Rica, 31, 1-15. DOI: http://dx.doi.org/10.15517/revenf.v0i31.22826

Introduction: The aim of this study is to reflect on the phenomenon of drug taking as a binding link the crack today.

Development: The scandal linked to the phenomenon of drug is not on the illegality of the action, or the risks of injury to health or financial cooperation with criminosas transitions; for this reason, for analysis they must be studied other contextual variables related to contemporaneity act in different economic, social, political, semantic and representational dimensions.

Conclusions: Drugs seen as commercial products should be treated as such, not only because they are immersed in a process of accumulation in a society that has characteristics strictly post-colonial and capitalist; but their behavior exchange, consumption, supply and demand makes them answer that own intrinsic reality of merchandises In this regard, the analysis of the phenomenon of drugs should be made from its historical particularity and contextualized the various implications of which come.

Key words: crack, drugs, illegal-drugs, legal-drugs

\footnotetext{
${ }^{1}$ Date of receipt: January 14, 2016

Date of acceptance: May 25, 2016

${ }^{2}$ Nurse. Doctoral Nursing Graduate Program in Nursing at the Federal University of Santa Catarina, Brazil (PEN / UFSC). Email: jaimealonso.caravaca@ucr.ac.cr
} 


\title{
Drogas na contemporaneidade: 100 miligramas de reflexões ${ }^{1}$
}

\author{
Jaime Alonso Caravaca Morera ${ }^{2}$
}

Instituição: Universidade Federal de Santa Catarina

\section{ENSAIOS}

\section{CITAÇÃO}

Caravaca, J.A. (2016). Drogas na contemporaneidade: 100 miligramas de reflexões. Rev. Enfermería Actual en Costa Rica, 31, 1 15. DOI: http://dx.doi.org/10.15517/revenf.v0i31.22826

\section{RESUMO}

Introdução: O seguinte estudo delimitou como objetivo refletir sobre o fenômeno do consumo de drogas, tomando como elo vinculante o caso do crack na atualidade.

Desenvolvimento: O escândalo vinculado ao fenômeno do consumo de drogas não reside na ilegalidade da ação, nem nos riscos de dano à saúde ou na cooperação financeira com as organizações criminosas; por esta razão, para sua análise devem ser estudadas outras variáveis contextuais relacionadas com a contemporaneidade da ação em suas diferentes dimensões econômicas, sociais, políticas, semânticas e representacionais.

Conclusões: As drogas vistas como produtos mercantis, devem ser tratadas como tais, não só porque se encontram imersas em um processo de acumulação em uma sociedade que apresenta características estritamente pós-coloniais e capitalistas; senão que seu comportamento de intercâmbio, consumo, oferta e demanda, faz com que elas respondam a essa realidade intrínseca própria das mercadorias. Neste sentido, a análise do fenômeno das drogas deve ser realizado a partir de sua particularidade histórica e contextualizada nas diversas implicações das quais procedem.

Palavras- chave: crack, drogas, drogas-ilícitas, drogas-lícitas

\footnotetext{
${ }^{1}$ Data de recebimento: 14 de janeiro de 2016

Data de aceitação: 25 de maio de 2016

${ }^{2}$ Enfermeiro. Enfermagem Doutorado do Programa de Pós-Graduação em Enfermagem da Universidade Federal de Santa Catarina,

Brasil (PEN / UFSC). Correio eletrônico: jaimealonso.caravaca@ucr.ac.cr
} 


\section{Revista Electrónica Enfermeria Actual en costa Rica}

\section{INTRODUCCIÓN}

El uso de sustancias con propiedades psicoactivas es una práctica que data desde tiempos remotos de la humanidad. Tanto en Oriente como en Occidente, innumerables culturas han desarrollado formas para trascender y manipular la consciencia, apoyándose muchas veces en la utilización de plantas consideradas sagradas (Caravaca, 2014).

Como elementos constitutivos en una serie de rituales tradicionales aparecían hierbas y brebajes, considerados fenómenos de gran eficacia simbólica, cuyas funciones eran relevantes para la historia e identidad de un grupo o comunidad específica. De esta forma, gracias a la polisemia de significados del fenómeno, fueron configurándose diferentes medios para comunicar y transmitir conocimientos relacionados con la utilización de estos compuestos herbales.

En algunos rituales, de acuerdo con los propósitos específicos, se buscaba alcanzar estados modificados de la consciencia humana, mediante la asociación (o no) con el uso de algunas sustancias. Cuando se utilizaban las plantas alucinógenas, se pretendía despertar estados de trance, los cuales se caracterizaban por la alteración de la percepción límbica del mundo y por estimular la discontinuidad de la realidad cotidiana (Escohotado, 1998).

El diálogo con otros rostros de realidades paralelas y planos espirituales diferentes, desempeñaba un papel obligatorio para algunas personas que componían el claustro histórico-cultural de grupos sociales específicos. La aparición de estos eventos era cuidadosamente delimitada y se daba de acuerdo con el respeto incondicional de convenciones, normativas colectivas, reglas y tradiciones especiales. Además, la administración de la sustancia no se destacaba más allá de un cuadro ampliado, al cual estaba referida y condicionada.

En la actualidad, aún podemos identificar una infinidad de modalidades en el uso (y abuso) de sustancias, circunscritas a momentos singulares y ceremonias especiales en las que se conserva en cierta medida la eficacia ritual del pasado. Sin embargo, existe una diferencia acentuada en relación con las antiguas formas de organización social, la cual reside en que en aquellas culturas la dimensión personal del consumo y su significación estaban sometidas al dominio colectivo e inscritas en la estructura del lenguaje mítico conexo a ellas (Dias, 2011).

Con todo, esta experiencia aún no autoriza comprender y conducir la droga del modo como fueron concebidas y entendidas en las antiguas culturas, por lo que es necesario rectificar la visión etnocéntrica de la práctica de la droga en las sociedades míticas, conservándose esta en el lugar de un correlato relativo al ritual.

Partiendo de este contexto tempestivo, presentado de forma sucinta, el objetivo del siguiente manuscrito se centra en reflexionar acerca del fenómeno del consumo de drogas, considerando como eslabón vinculante el caso del crack. De esta manera, se intenta revelar el panorama axiomático y práctico asociado a las prácticas consumidoras en la contemporaneidad, realizando un recorrido interseccional por las diferentes esferas históricas, ontológicas, sociales, políticas, económicas y culturales intrínsecas en esta realidad performativa. 


\section{Revista Electrónica Enfermeria Actual en costa Rica}

\section{DESARROLLO}

\section{Sobre el advenimiento del consumo: configuraciones históricas y antropológica de los rituales y las sustancias psicoactivas}

La noción de individuo y los orígenes económicos del consumo en la modernidad, develan que el inicio de dicha época estuvo acompañado de la gran aparición de una categoría fundamental que abrió camino para que, en los tiempos contemporáneos, se pudiesen desarrollar relaciones privativas en el consumo de drogas, distanciándose de la dimensión ritualista y colectiva anteriormente descrita. La noción de individuo y la centralidad de la experiencia humana descollaron en la escena social, afianzándose como valores soberanos en este nuevo orden colectivo.

A su vez, la modernidad está centralizada en el individuo y la individualidad es la categoría fundamental que define el ideal de este proyecto temporal consolidado durante la Revolución Industrial, motivo por el que está normalmente relacionado con el desarrollo del capitalismo. Ante lo expuesto, es importante resaltar que el proyecto de la modernidad es antropológico y antropocéntrico, justamente porque el hombre en su calidad de individuo fue exaltado y llevado a la condición primordial de supremacía sobre todas las cosas.

El dominio del cuerpo, su posesión y usufructo también fueron subordinados a la voluntad y al control de cada individuo. En este sentido, el manejo de impulsos, afectos y sensaciones se tornaron prerrogativas particulares, proceso que tuvo como resultado una sociedad de individuos. Dicho proceso inició a finales del siglo XIV y se completó en las cortes del siglo XVIII, al término del cual cada ser humano era considerado como un ser aislado de todos los otros y responsable por el control soberano de su cuerpo, sus impulsos, deseos y afectos (Bauman, 2005).

Sin embargo, fue gracias a la economía capitalista que la disposición de la droga sufrió un impacto significativo, por el que adquirió otra connotación, expresa por la lógica del mercado, con la cual se permitió su distribución y disponibilidad como producto de compra. Aquel consumo que era más localizado en ciertos grupos culturales, en ciertas minorías y en ciertos estratos sociales, pasó a ser dictado no más por la lógica de las tradiciones o de la élite, sino por la del mercado, del capital.

Para tratar este nuevo panorama de la droga como objeto de oferta y demanda, es necesario detenerse en las condiciones esenciales que tornaron posible el advenimiento del consumo y su derivación más frenética, es decir, el consumismo.

Paralelamente, el incremento de la productividad industrial generó cambios permanentes en el carácter y en el sentido de la actividad del trabajo, cuya naturaleza artesanal se extinguió. La transformación de la materia bruta en objetos durables que conservaran el empeño y el hacer humano, cuyo valor residiese en su carácter utilitario, fue asumida por el engranaje productivo que pasó a orientarse en una imperiosa necesidad del rápido descargue de interminables existencias.

En esta ecuación (im)productiva, correspondió al trabajador vislumbrarse como parte de una maquinaria multiplicadora de elementos (necesarios o no), destinados al acto dinámico y plausible de la venta. Con la 


\section{Revista Electrónica Enfermeria Actual en costa Rica}

resemantización del trabajo en labor, el margen de expiración compareció para dictar el tiempo de usufructo y de substitución de los productos, estrechando su vida útil.

La transformación del proceso de trabajo introdujo una innovación cultural, en la cual el principio de la utilidad pasó de poseer un valor fundamental a poseer uno secundario; una vez que la producción y la compra de los objetos se subordinaron primordialmente a la idea de felicidad absoluta, se dirigió al consumidor hacia el beneficio del placer que este podría extraer de la vida.

Para ampliar este debate, es necesario problematizar ciertos equívocos que sustentaron la cuestión del consumismo. Aunque el modo de producción a larga escala y, por lo tanto, el aumento vertiginoso del factor económico hayan proporcionado las condiciones para el establecimiento del consumo, el mismo, por sí, no explica o justifica ese hábito. Es decir, no basta que haya alta productividad y objetos disponibles en exceso, para que se establezca una motivación para consumir. De ahí, la necesidad de una red social, simbólica, estructural y emocional que ofrezca sentido y pertinencia a tal práctica.

Otro punto que merece ser mejor redelineado es el que se relaciona con la insatisfacción, que sería el epígrafe resultante en el consumismo ("consumistas insatisfechos" e "insatisfechos-consumistas"), por lo que el consumismo y la insatisfacción estarían fatal e inequívocamente entrelazados (Dias, 2011).

El consumismo puede ser situado como una acción que se orienta a la búsqueda de nuevas fuentes de placer y, en este caso, hay una insatisfacción no solo intencionada como perfectamente susceptible de realizarse sin miramientos. Además, la compra de objetos no presume fatalmente la condenación de su consumidor a una vida emocional obtusa y estropeada, supuestamente basada en la adquisición de productos de carácter superfluo y en portadores de la marca de la alienación (Dias, Araujo y Laranjeira, 2011).

En realidad, los teóricos al decir que los individuos son crónicamente insatisfechos (porque son consumistas), no están considerando un hecho, sino emitiendo un juicio moral, en el cual la satisfacción psicológica obtenida con la compra de objetos es interpretada como insatisfacción porque sería un tipo de realización emocional ilegítima.

No hay nada que lleve a suponer que los individuos viven en una especie de trance consumista, inducido por la fuerza de la publicidad (aunque sí del capitalismo), como algunos investigadores quieren hacer pensar; por ende, el consumo no figura de forma indudable como la antítesis de la satisfacción o de un modo de vida más expandido, pues perfectamente puede alinearse con el desarrollo de las emociones y el interés ético por el otro.

La gran tradición artística o moral de las élites occidentales probablemente no hubiera tenido el alcance que tuvo, sin la compra de objetos industriales destinados al cultivo de los espíritus en materia de política, música, filosofía, religión, literatura, entre otros. Además de estos, otros innumerables objetivos extra-personales se apoyaron en la compra de objetos físicos o simbólicos para (auto) realizarse.

Una vez dislocado el foco del fantasma del consumo como el verdugo martirizante de nuestros tiempos, se podrían ahora problematizar las repercusiones oriundas de las mudanzas de nuestras creencias éticas, a lo largo del siglo XX e inicio del XXI, en la función y apropiación emocional de los productos (Escohotado, 1998), 


\section{Revista Electrónica Enfermeria Actual en costa Rica}

partiendo de la premisa que afirma que el sentido acuñado a los objetos se subordina a la interacción del individuo con el mundo, por la que es importante reconocer la moral y los ideales sociales vigentes para entender el modo como se da la relación con el consumo y los objetos (incluyendo aquí el concepto de la droga).

Vincularse con este o aquel producto, en relación con la calidad, frecuencia, grado de involucramiento, inversión o intensidad determinada, representa un modo de respuesta a ciertos ideales de felicidad. ¿Cuál sería entonces la moral de los tiempos en los que vivimos?

Uno de los cambios operados en la actualidad reside en la exigencia y determinación del mercado de trabajo que nace como fruto de las innovaciones tecnológicas y de la era de los grandes conglomerados. Con la escasez de espacios y oportunidades, y la competencia económica, la figura del trabajador necesitó adaptarse a un escenario en el que el ambiente (y el propio trabajo) no se manifiesta más que como lugares promisorios en el sentido de la posibilidad de larga permanencia y constitución de un lugar de pertenencia y seguridad.

El profesional considerado como "calificado" pasa a tener que exhibir competencias interpersonales indispensables dictadas por cierto desapego y superficialidad en el contacto diario y en sus interrelaciones personales. Necesita también, mantener un "juego de cintura, equilibrio y sensatez" además de ser hábilmente maleable y estar dispuesto a aceptar nuevos desafíos, repaginarse, reciclarse, desmembrarse e incorporar(se) nuevas tendencias y tecnologías; en otras palabras, el profesional del siglo XXI, debe camaleónicamente tornarse en un sujeto adaptable a las exigencias mutables y exigidas por el medio donde desarrolla sus actividades diarias. La imagen que bien resume esta nueva identidad de persona ideal es la de un "turista", siempre abierto a lo indeterminado, a las nuevas adquisiciones, vivencias y perspectivas futuras, que no se apega a conservadorismos o identidades pasadas; que hereda el gran arte de no acumular y, muy por lo contario, que exhibe trazos de personalidad de individuos que saben desechar, descartar y olvidar rápidamente.

Para armonizarse con esta (no tan) "nueva" visión de mundo, el propio perfil de los objetos también fue modificándose: deben siempre remitir a lo actual, a lo mejor y a lo de última generación y necesitan ser utilizados sin mucho apego, ya que después serán prontamente substituidos por otro más avanzado (¿mejor?). La dirección apunta para un porvenir de un flujo cinético, continuo y rápido de personas y cosas entrando y saliendo de un espacio sin "calentar un lugar".

¿Cómo no articular la oferta pungente de nuevas drogas hermosamente arrojadas por avanzadas técnicas de laboratorio (design drugs), con el inmediatismo y la brevedad de sus efectos, así como con las frecuentes substituciones por otras más potentes e inéditas, al contexto de esta lógica?

Dado lo anterior, se relaciona en este trabajo el segundo acontecimiento sociocultural mediador de la relación con los objetos de consumo, con la presentación del cuerpo y su papel en la formación de las identidades individuales, corroborado por el crecimiento del papel de la media digital.

Bajo la tutela de la moral del espectáculo y de exponer (casi violentamente) "todo lo que soy mediante lo que tengo", el culto al cuerpo gana fuerza. El universo particular asume contornos de plausibilidad y codicia colectiva: todos quieren imitar el mejor estilo de vida de los ricos, poderosos y famosos. Como las oportunidades de ascender socialmente son bastante limitadas, el cuerpo o, mejor dicho, la imagen del cuerpo saluda, en la 


\section{Revista Electrónica Enfermeria Actual en costa Rica}

fantasía, como trampolín de acceso al territorio de pocos, signo de prestigio y distinción social, o sea en una manera de estar visible en "el aquí y el ahora".

El cuerpo performático, moldeado para ser visto y envidiado, conquistó el privilegio y la atención del individuo en detrimento de la vida sentimental. La idea de bienestar se equiparó a la de bienestar sensorial, o sea, al culto de las sensaciones. Cuidar de sí se tornó en cuidar del cuerpo. En este escenario, también el sentido de los objetos sufrió alteración, entrelazándose al tipo de placer y de felicidad deseado y perseguido.

En la felicidad sensorial, el placer está condicionado a la presencia física y constante del objeto de estímulo. La satisfacción no acontece en la ausencia de él, en otras palabras, el registro de las experiencias vividas no es capaz de activar o reproducir el placer deseado, no hay rememoración, tampoco evocación discursiva que consiga recuperar o extender tal placer más allá del encuentro real (Gabatz, Schmidt, Terra, Padoin, Silva y Lacchini, 2013).

Los recuerdos de las experiencias sensibles no se dejan metaforizar como las imágenes y narrativas sentimentales. Fuera del instante del gozo, la sensación es emocionalmente obsoleta. Su evocación raramente proporciona el nivel de placer que la reminiscencia de los sentimientos pueda proporcionar. Por esa razón, la felicidad sensorial necesita ávidamente de objetos que estén a la mano y que puedan ser velozmente instrumentalizados.

El objeto adecuado es aquel que está más rápidamente a disposición, por lo que causa sensaciones esperadas. En la economía libidinal de las sensaciones, el mejor objeto es aquel que excita los sentidos, despertando el cuerpo para una nueva sensación placentera: drogas, psicoestimulantes, medicamentos, bebidas energéticas, tónicos, hormonas, prótesis orgánicas o mecánicas, instrumentos que transforman la fuerza mecánica en fuerza o plasticidad muscular.

La tercera alteración en el empleo y la aparición de los objetos se relaciona con la mudanza en el estatuto de la autoridad y sus fundamentaciones. La sabiduría calcada en la tradición, en la transmisión de valores y principios de generación por generación, dio lugar (en la actualidad) a la figura de lo transitorio, a la celebridad. La cultura de la celebridad pone en destaque un nombre, que tiene el poder de guiar y orientar una infinitud de seguidores hasta que este sea olvidado, ya que posteriormente será substituido por otro personaje.

A diferencia de la autoridad caracterizada por la unión de la notoriedad y el talento, en el caso de lo célebre, su visibilidad se apoya en el potencial de entretener. Este último se caracteriza por acciones repetitivas y (poco) estériles que llegan a tornarse predecibles.: es el señuelo travestido de éxito y merecimiento. La sociedad de los ciudadanos transformada en abstractos índices de audiencia vive en un impase: se debe escoger entre la responsabilidad moral con exilio social o la inconsecuencia moral socialmente recompensada: es el dilema entre el bolsillo o la decencia.

La relación con los bienes y objetos en la moral del entretenimiento es transformada en anzuelos, por el producto trofeo que se expresan como coronamiento a los fútiles, y desdén, por el reconocimiento del vaciamiento ético perpetrado por esa misma moral. 


\section{Revista Electrónica Enfermeria Actual en costa Rica}

Parte del apelo provocado por la droga en la cultura de la celebridad se asienta en esa misma lógica de la búsqueda repetitiva por el entretenimiento: drogarse para experimentar una avalancha de sensaciones, pasar el tiempo o anestesiar sus aburrimientos o problemas. No se puede dejar de considerar también el anzuelo producido por la sustancia, cuya promesa de continuidad de satisfacción no es sustentada. Hay aún un proceso de vaciamiento subjetivo y social que se sigue al consumo intensificado de la droga; un correlato del vaciamiento del sentido de la vida en la moral vigente.

Aunque aún podamos ser testigos de una amplia gama de usos para las drogas (lúdicos, sagrados, terapéuticos), las relaciones de consumo de carácter frecuente e intensificado se han expandido y han demandado una cuidadosa atención.

Al respecto, aunque estas prácticas se procesen en niveles individuales y consonantes a los intereses particulares (condición de posibilidad conquistada y fomentada a partir de la modernidad), no hay cómo desconsiderar la implicación de los ideales colectivos actuales en la constitución del fenómeno; por tanto, habría que definir mejor el estatuto de esas relaciones de consumo, concibiéndolas en su totalidad, como síntomas sociales (aunque atraviesen al individuo, sean apropiadas por él y ganen a partir de ahí un significado específico en su vida y comunidad) (Dias, 2011).

No basta que un número de individuos en una comunidad sea alcanzado por algo para que se transforme en un síntoma social; por ejemplo, puede existir un cierto porcentual de fóbicos en una determinada población sin que se transforme esta fobia en un síntoma social. Pero se puede hablar de síntoma social a partir del momento en que la toxicomanía es de cierto modo inscrita y diseñada en una realidad hasta causar una serie de variaciones en ese contexto, aunque este fenómeno acontezca en las entrelíneas, de forma no explícita, no articulada como tal y en el discurso dominante de una sociedad y espacio temporal determinado: solamente es en este sentido es posible hablar de síntoma social.

De esta manera, no sería el registro estrictamente estadístico el que justificaría la pertinencia de un asunto como síntoma social. Sin embargo, sería posible encontrarla (o no) esculpida en las intercalaciones subterráneas del discurso hegemónico. Como síntoma social, las relaciones intensificadas de consumo no pueden ser tomadas como fenómenos separados y ajenos del orden vigente, ya que de los ideales sociales advienen muchas de las condiciones para su fortalecimiento en cuanto acontecimiento y modo de respuesta a ellos.

En esta línea de análisis, sería ingenuo entonces pensar exclusivamente en la remoción quirúrgica de las drogas del cuerpo social, una vez que este viene a proveer las bases para la necesidad impetuosa de su empleo. En este caso, un real enfrentamiento de la cuestión no puede acontecer sin que se problematice la moral dominante que, como tal, es compartida por todos.

No es difícil situar las relaciones de consumo de drogas como modalidades de respuestas a los ideales de felicidad mencionados. La administración de la droga responde al apelo por nuevas y emocionantes aventuras, entretenimiento, excitación de los sentidos y perfeccionamiento corporal, se apela también a la intensificación de poderes y desempeños individuales, entre otros más. La moral vigente insiste en sugerir que el éxtasis químico que las drogas proveen, es la entrada pavimentada a la felicidad total (Dias, Araujo y Laranjeira, 2011). 


\section{Revista Electrónica Enfermeria Actual en costa Rica}

El escándalo del uso de drogas no reside en la ilegalidad de la acción, ni en los riesgos de daños a la salud o en la cooperación financiera con las transiciones criminosas. Todo esto, obviamente es nefasto y destructivo. Lo más sorprendente es que ninguno de estos argumentos consigue encaminar a las personas a abandonar esos hábitos (muchas veces destructivos): los adultos y adolescentes conocen extensamente los efectos personales y sociales del uso y abuso de drogas y si no desisten a usar las drogas es porque reconocen en voz alta y clara lo que se lucha por admitir: el comercio de las drogas es sordo y todo vale la pena por la sensación de un placer, aunque este sea fugaz. Por casualidad, ¿esto representa en un lenguaje simbólico falta de ganas de vivir?

Así, tratar las modalidades de consumo de drogas como aberraciones o como comportamientos destructivos, opuestos al orden hegemónico, implica dejar escapar lo que esos fenómenos nos revelan respecto a las expectativas e ideales que sustentan las relaciones sociales y que, por lo tanto, en mayor (o menor) grado, dejan sus marcas en lo cotidiano y modos de vida en la colectividad.

\section{LAS RAÍCES DE LA DROGA: Sobre la realidad del crack}

Un aspecto crucial que ayuda en la delimitación del asunto y en la reflexión del abordaje analítico del fenómeno de las drogas, consiste en el enraizamiento de una noción de droga en el saber determinado por el discurso de la ciencia. La droga como elemento científico se convirtió en un aparente compuesto toxicológico, sin embargo, la comprensión contemporánea de todo fenómeno que la involucra exige realizar una previa identificación de la verdadera naturaleza tóxica de sus componentes. En este trabajo, se parte del presupuesto que la droga no es un mal en sí, ya que comporta una serie de usos posibles y está inexorablemente condicionada a la finalidad y significación a la que está invertida por quien la utiliza. Además, se entiende que existe una interacción dinámica en el entrecruzamiento de la droga y las dinámicas de consumo, teniendo en consideración elementos significativos en esta ecuación tales como efecto, dosis, pureza, toxicidad, grado de tolerancia, individuo y contexto sociocultural en el que se participa.

Como ejemplo para abordar tal fenómeno, se utilizó al crack $^{1}$, con el objetivo de profundizar y detallar explícitamente algunas relaciones actuales que existen en la conexión sociedad-droga, por medio de la consideración de aspectos subjetivos, familiares, orgánicos, farmacológicos, sociales, económicos, políticos y culturales, que determinan la transformación de las subjetividades y existencias ontológicas de modo radical, alterando las relaciones del individuo consigo, con los otros y con la vida.

Particularmente en relación con la droga en cuestión (crack), parece bastante oportuno desarrollar un punto relevante: la necesidad de colocar en cuestión la retórica en torno a la droga, que continuamente es producida y reproducida en el cuerpo social, por medio de la extensión de adhesivas iconografías en el imaginario colectivo y en el direccionamiento de las acciones (Sapori y Medeiros, 2010).

En el campo analítico, cualquier estudio que aborde el uso y abuso de drogas, debe comenzar por el hecho de que la planta o hasta la propia sustancia producida en análisis de laboratorio o por la síntesis química, son entes

\footnotetext{
${ }^{1}$ Se podría problematizar aquí el empleo de la expresión "el crack", cuestionando si no se trata de una abstracción, ya que no hay como considerar una droga en estado bruto por sí sola, dotada de existencia absoluta, independiente de su red de relaciones y sentidos.
} 


\section{Revista Electrónica Enfermeria Actual en costa Rica}

pasibles del emprendimiento del lenguaje y, consecuentemente, susceptibles a diferentes modalidades de efectos de sentido y significación en el plano del saber.

A lo largo de los últimos años se ha construido una retórica vigorosa y resistente sobre el crack, entendida no como la simple expresión del habla, sino como la práctica explícita del discurso que produce efectos concretos (posicionamientos y actitudes) de acuerdo con determinados modos de enunciación; en otras palabras, hay noción de droga que no sea relativa al contexto discursivo en el cual ella se enuncia, forma en la que aparecen algunos ornamentos metafóricos relacionados a diferentes sustancias psicoactivas (Caravaca-Morera y Padilha, 2015).

Aunque este trabajo específicamente no se ocupe de las condiciones clínicas, la crítica se torna provechosa y adecuada para cuestionar los discursos y sentidos que se produjeron en torno al consumo/usuario de crack, designando una postura satanizada, que debe ser relativizada, (re)pensada y problematizada. La pertinencia de interlocución con esas ideas revela metáforas que proliferan al respecto de esa sustancia (analogías sutiles que la relacionan con llagas, muertes, terrores, flagelos y calamidades) entre amplios sectores de la sociedad. No está en juego aquí, tomar o no las relaciones del uso de crack como enfermedad. El diálogo propuesto se relaciona con la necesidad de desvendar los sentidos morales que vienen siendo construidos para la droga y sus implicaciones éticas.

De esta forma, se exhorta a reflexionar sobre el contenido de las evocaciones que establecen reiteradas asociaciones entre ciertas condiciones clínicas y potenciales riesgos de mortalidad, ya que la existencia de algún elemento tóxico en los venenos naturales o artificiales frecuentemente mortales, no es suficiente para definir en el imaginario lo que es considerado una droga. La asimilación unilateral de la palabra droga a un factor tóxico supone una equivocada reducción y restricción de su campo de sentido. Por otro lado, la apropiación de este fragmento de la realidad resulta en la imposición de una absoluta exigencia cuando se analiza la pretensión científica de definición (in)congruente de la droga.

Entonces, presentar algunas significaciones que relacionan la droga como "depredadores invencibles y malignos" o verdaderas sentencias de muerte (incluyendo campañas de "el crack mata") ilustra iniciativas que van más allá de una (más o menos) bien intencionada campaña de salud colectiva dirigidas al cuidado y atención de los ciudadanos (Sapori y Medeiros, 2010; Bastos y Bertoni, 2014).

El direccionamiento de la problemática a partir de esta tonalidad del discurso trae serias implicaciones prácticas, en la medida en que provee autorización (o justificación) para la adopción de medidas contundentes de control y tutela, que surgen transfiguradas sobre un supuesto disfraz que licencia la protección de la droga. Las propuestas de internación obligatoria en serie ganan fuerza a partir de esta vertiente discursiva y tienden a encontrar apoyo en el miedo que adviene de la ejecución de este tipo de asociación.

La desinversión en la oferta de cuidados, así como el descrédito en el usuario ("esta persona no tiene solución", "con él o ella no hay nada más que hacer"), también figuran como efectos posibles del discurso apuntado, que interfieren en la conducción del trabajo por parte de los equipos de atención en salud.

$\mathrm{Al}$ respecto, existe actualmente un énfasis negativo dado a los usuarios de crack que transforma el crack en "un dragón de siete cabezas". Los mitos y exageraciones construidos en torno del crack, en los últimos tiempos, al 


\section{Revista Electrónica Enfermeria Actual en costa Rica}

contrario de lo que muchos piensan, más allá de haber desviado el foco del usuario abusivo - que debería ser el protagonista de este fenómeno- contribuyen para que la sociedad en general y los órganos estatales proporcionen al problema una magnitud exagerada, concomitante con las posturas y actitudes políticas desesperadas vistas en los diferentes medios, como la invasión y destrucción de los lugares de consumo, la proposición de un plano nacional de combate al uso de drogas (con la propuesta de internación compulsoria) y el lanzamiento de campañas apelativas en los medios, entre otros (Bauman, 2005; Dias, 2011).

En medio de esas medidas desesperadas e ineficaces, el crack se torna en ese "dragón de siete cabezas", mencionado, en el actual contexto social no solo costarricense, sino latinoamericano. En relación con lo anterior, existe, según algunos investigadores, una verdadera aprobación de estigmas (auto-estigma, estigma público, estigma estructural, estigma institucional) alrededor del individuo que consume esa sustancia, lo que dificulta la (auto) búsqueda de un tratamiento adecuado.

Por otra parte, cuando acontece esa autorreferencia en búsqueda de ayuda, se evidencia una falta de preparación por parte del profesional de salud, para brindar una atención calificada. En torno al tema, Bastos y Bertoni (2014) fueron testigos de las resistencias existentes respecto de este acogimiento de los usuarios de crack, a cargo de los profesionales de salud que atienden la demanda específica de usuarios de drogas, una actitud que ciertamente impregna sus repercusiones en la adhesión al tratamiento.

El anterior aspecto merecer ser discutido, más cuando se verifica un gran contingente de estudios que atribuyen al usuario de crack bajos índices de adhesión y retención en servicios de tratamientos. Por ello, surge la siguiente pregunta ¿en qué medida tales índices estarían entrelazados a atributos individuales o serían los síntomas de un cuadro mucho más complejo, cuyas determinantes incluyen los significados (re)producidos en torno de la droga, diseminados socialmente y compartidos por los profesionales que prestan atención al usuario?

De igual modo, existe además un tipo insidioso de retórica, presente en las campañas preventivas y discusiones sobre el crack, que transforma la sustancia en el atestado de un supuesto descamino o bancarrota social. El terror producido por su reiterado empleo (como un aviso de lo que puede acontecer a quien a él se aproxime) tiende a provocar cierto embrutecimiento de la consciencia, al mismo tiempo que captura y restringe el ejercicio del pensamiento crítico, como también moviliza fuerzas en dirección de una especie de "contemplación estoica de la catástrofe".

La necesidad de realizar previsiones pesimistas por parte de algunos entes políticos y profesionales de salud, refleja la subsecuente necesidad de (re)producir un miedo contra aquello que es considerado incontrolable, lo que consecuentemente revela una baja complicidad imaginativa con la verdadera naturaleza del fenómeno (Sapori y Medeiros, 2010; Dias, Araújo y Laranjeira, 2011; Dias, 2011; Caravaca-Morera y Padilha, 2015).

Sería interesante pensar en la premisa de una "sociedad sin drogas" o en "un mundo libre de drogas" como una voluntad mágica de recomienzo, retomando el idilio social perdido ("cuando todo funcionaba bien", pero se debe preguntar ¿cuándo todo funcionó bien?). Exprime también una tentativa de control del Estado respecto de cosas que se suponen desgobernadas y, por lo tanto, mucho más allá de lo que se puede caminar en el sentido de la construcción de senderos posibles. 


\section{Revista Electrónica Enfermeria Actual en costa Rica}

La concepción de catástrofe y de desgobierno, a su vez, se armoniza (y tiende a legitimar) con la elección de una causa y un enemigo a ser supuestamente combatido, mas no todas las metáforas aplicadas a las enfermedades y a sus tratamientos son igualmente ofensivas y deformantes. La metáfora que interesa superar, con mucho más ímpetu, después del surgimiento del SIDA, es la de asociación (des)armónica de combate militar, ya que el efecto de las imágenes militares sobre la conceptualización de la enfermedad y de la salud, está lejos de ser irrelevante. Ellas provocan una movilización excesiva, una representación exacerbada y dan una contribución de peso para el proceso de repudio, excomunión y estigmatización del usuario de drogas.

La idea de medicamento "panaceico" que cura el uso/abuso de sustancias psicoactivas es tan indeseable como la de guerra combativa contra las drogas y sus usuarios. El cuerpo no es un campo de batalla. Los usuarios no son las bajas inevitables, ni tampoco son los enemigos. Nosotros, la enfermería social y la sociedad, no estamos autorizados a combatir todo y por cualquier medio (Escohotado, 1998; Caravaca-Morera y Padilha, 2015).

Como se mencionó, las metáforas se hacen presentes, de modo general, en las concepciones cultivadas por la orden conminatoria "guerra a las drogas" y, de forma específica, en las conductas sugeridas para el combate contra el crack. Estas últimas, algunas veces, se sustentan en modelos de pensamiento, acción y decisión unilaterales que carecen de escucha de los verdaderos actores sociales (profesionales, usuarios, familiares y aliados/correlacionados) involucrados en la cuestión. Se apoyan en la lógica inmediata del resultado y se socorren en recetas predefinidas, aplicables al amontonamiento, mientras se descartan las singularidades y la necesidad de intervención "a la medida justa".

Es innegable que el crack como fenómeno merece y debe ser tratado con la seriedad que él conlleva, mas pronosticarlo por la vía de la amenaza (más allá de los riesgos probables) e incitar el miedo (distancia), es fomentar estigmas al usuario, potencializando la marginalización y la exclusión social, puesto que el propósito original del tratamiento del fenómeno reside en todo lo opuesto; es decir, en la implementación de estrategias de aproximación, integración y circulación de experiencias y saberes (Dias, 2011).

Lo anterior no significa que su uso sea inofensivo o exento de riesgos, sin embargo, la imagen vehiculada refuerza la discriminación del usuario, lo cual aumenta aún más la distancia entre los usuarios y los no usuarios, en la que los segundos son parte de un eslabón importantísimo en una perspectiva de inclusión sin la cual no se conseguiría minimizar los efectos dañinos de su uso.

Lo importante aquí es considerar el "crack" como un fenómeno que implica la basta totalidad de la sociedad (en latín, res publica) o sea, como un asunto que concierne a la colectividad, se concuerde con ella o no. Sin embargo, el compromiso con este relevante asunto necesita fundamentarse en el ejercicio de la reflexión, en la problematización de los intereses en juego y en la crítica de la disputa por la "retórica del crack", la cual restringe y dificulta la consideración del fenómeno a partir de otros referenciales y potencialidades.

Es necesario, aún más garantizar el acceso a la información y discusiones calificadas, lo que, desde el punto de vista de los medios de comunicación, apunta a otro problema, puesto que la relación con la noticia se hace cada vez más a partir de otras alianzas y conjuntos de intereses que disfrazan sus diferentes aristas, lo cual dificulta la orientación en la exactitud del fenómeno de la droga. 


\section{Revista Electrónica Enfermeria Actual en costa Rica}

No es suficiente que los acontecimientos sean por sí solo expuestos con titulares explosivos, confeccionados de forma llamativa o que tengan encabezados aulladores en las ediciones impresas o audiovisuales. Los diferentes canales de comunicación necesitan movilizar todas las fuerzas específicas de su género y entregar la noticia contemplando los diferentes rostros que el fenómeno presenta, para lograr una inyección multisensorial e integral de manera que alcance diferentes niveles de comprensión y subjetividad colectiva.

Lo más perceptible es que justamente la alta presión noticiosa del presente asunto, asocia automáticamente la "sensación" con el "causar una sensación", lo que no escasamente sobrepone la cuestión inicial al sentido fisiológico antiguo, sino que lo moviliza a una nueva forma ontológica. Entonces, sobre esa línea de raciocinio, si todo lo que no está en condiciones de causar una sensación tiende a desaparecer sobre el flujo de las informaciones, prácticamente apenas lo que genera una sensación será percibido. Así, la percepción de lo que causa una sensación se convierte en una percepción per se, en el caso extremo de la percepción en instancia normal.

Se puede afirmar que el receptor de la información está continuamente afectado por la violenta e impactante estimulación sensorial que acompaña la noticia y, asimismo, en algún momento se amalgama de modo que pasa a formar parte indisociable de ella (tal como la acción y el efecto de una droga) (Dias, 2011).

$\mathrm{Si}$, por un lado, la respuesta al retumbante señuelo noticioso es inmediata; por otro, la atención no se sustenta, pues se debe tener en consideración el exceso de estímulos y el estado de hipersaturación perceptiva a la que sus espectadores son impuestos. Una especie de anestesia parece establecerse en el nivel basal de la sociedad, hasta que una nueva "vibración" sea transmitida. La dimensión reflexiva de la experiencia es substraída y subsumida por la información "adrenalizada" que busca insistentemente capturar los sentidos.

El consumidor de la noticia es hoy un usuario de intensas sensaciones, ansioso por una nueva bomba de escándalos estigmatizadores. En este sentido, el crack se ha presentado como uno más de los poderosos estimulantes capaces de encender las percepciones y capaz de causar una enorme sensación en su público consumidor, lo cual coloca al espectador en el desafío de la cuidadosa depuración y discernimiento de los exacerbados efectos de enunciación engendrados alrededor de esta y otras drogas.

\section{CONCLUSIONES}

No es raro, observar, en determinados debates públicos, posicionamientos que sitúan a las drogas (como el crack) y sus efectos psicoactivos, como una especie de agente responsable por las más variadas formas de antagonismo social, cual villano de la contemporaneidad. No obstante, no parece que este sea un camino posible y coherente para estudiar la droga. Se debe resaltar, primeramente, que las drogas son productos de las relaciones sociales históricamente delimitadas y responde, como producto de consumo, a determinados deseos, deleites y necesidades propias de cada época.

Por otro lado, las drogas vistas como productos mercantiles, deben ser tratadas como tales, no solo porque se encuentran inmersas en un proceso de acumulación en una sociedad que presenta características estrictamente post-coloniales y capitalistas; sino que su comportamiento de intercambio, consumo, oferta y demanda, las hace 


\section{Revista Electrónica Enfermeria Actual en costa Rica}

responder a esa realidad intrínseca propia de las mercadurías para generar valor en la esfera de producción y circulación.

En este sentido, el análisis del fenómeno de las drogas debe ser realizado a partir de su particularidad histórica y contextualizada a las implicaciones económicas, políticas y sociales de las cuales descorren. Tomando otra dirección, pero sin pretender agotar el entendimiento en el tema vigente, se propone relativizar la visión de criminalización de las drogas y sus usuarios, con la finalidad de ampliar nuestros paradigmas de atención, hacia procesos de cuidado integral, comprensivo y desestigmatizador.

De esta manera, utilizando una visión ampliada sobre el fenómeno que articule no solo las determinantes económicas involucradas, sino otras relacionadas con contemporaneidad, sexo, raza, identidad de género, cuerpos, sexualidades, materialidades y subjetividades, se podría alcanzar una resignificación del fenómeno que favorezca la relectura antinecropolítica de los usuarios y la droga en general.

\section{REFERENCIAS BIBLIOGRÁFICAS}

Bastos, F. y Bertoni, N. (Eds.). (2014). Pesquisa nacional sobre o uso de crack: Quem são os usuários de crack elou similares do Brasil? Quantos são nas capitais brasileiras? Rio de Janeiro, Brasil: ICIT/ FIOCRUZ.

Bauman, Z. (2005). Vidas desperdiçadas. São Paulo: Editorial Zahar.

Caravaca, J. (2014). Crack: el inicio de la piedra en Brasil. Rev. Enfermería Actual en Costa Rica, 27, 1-11.

Caravaca, J. y Padilha, M. (2015). A dinâmica das relações familiares de moradores de rua usuários de crack. Saúde em Debate, 39(106), 748-759.

Dias, A., Araújo, M. y Laranjeira, R. (2011). Evolução do consumo de crack em coorte com histórico de tratamento. Revista de Saúde Pública, vol. 45, no. 5, p. 938-948.

Dias, A. (2011). Crak: Reflexões para Abordar e Enfrentar o Problema. Rio de janeiro: Editorial Civilização Brasileira.

Escohotado, A. (1998). Historia general de las drogas. 7. ed. Madrid: Alianza.

Gabatz, R., Schmidt, A., Terra, M, Padoin, S., Silva, A. y Lacchini, A. (2013). Percepção dos usuários de crack em relação ao uso e tratamento. Revista Gaúcha de Enfermagem: v. 34, no. 1, p. 140-146.

Sapori L. y Medeiros R. (2010). Crack: um desafio social. Belo Horizonte: Editora PUC Minas. 